\title{
Muscle Injury After Intramuscular Administration of Diclofenac: A Case Report Supported by Magnetic Resonance Imaging
}

\author{
Mareike Probst $^{1}\left([) \cdot\right.$ Jens-Peter Kühn $^{2,3} \cdot$ Christiane Mode $^{4} \cdot$ Eberhard Scheuch $^{4}$. \\ Anne Seidlitz $^{1} \cdot$ Norbert Hosten $^{2} \cdot$ Werner Siegmund $^{4} \cdot$ Werner Weitschies $^{1}$
}

Published online: 25 March 2017

(C) The Author(s) 2017. This article is an open access publication

\begin{abstract}
Intramuscular injection of diclofenac is still frequently practiced, although there is ample evidence that the risk of local tissue intolerability is highly underestimated. The aim of this study was to evaluate local toxicity in a patient using magnetic resonance imaging. A patient who gave written informed consent received a medically indicated intramuscular administration of diclofenac $75 \mathrm{mg} / 2 \mathrm{~mL}$. Simultaneously with magnetic resonance imaging of the depot, a clinical-chemical evaluation and quantification of diclofenac in plasma was performed. A manifold enhancement of the T2-weighted magnetic resonance signal was observed in a muscle area of approximately $60 \mathrm{~mL}$ volume, with maximum signal intensity 30 min after injection, the time of maximum diclofenac plasma exposure. Plasma creatine kinase activity was elevated approximately sixfold within $8 \mathrm{~h}$ and normalized within 1 week, whereas the magnetic resonance enhancement disappeared within 5 weeks. Interestingly, the patient
\end{abstract}

Mareike Probst

mareike.probst@uni-greifswald.de

1 Department of Biopharmaceutics and Pharmaceutical Technology, Center of Drug Absorption and Transport (C_DAT), Ernst Moritz Arndt University Greifswald, FelixHausdorff-Straße 3, 17487 Greifswald, Germany

2 Institute of Diagnostic Radiology and Neuroradiology, University Medicine Greifswald, Ferdinand-SauerbruchStraße, 17475 Greifswald, Germany

3 Institute of Radiology, University Medicine, Carl Gustav Carus UniversityDresden, Fetscherstraße 74, 01307 Dresden, Germany

4 Department of Clinical Pharmacology, Center of Drug Absorption and Transport (C_DAT), University Medicine Greifswald, Felix-Hausdorff-Straße 3, 17487 Greifswald, Germany did not complain about any clinical symptoms at the injection site. Asymptomatic tissue injury after intramuscular injection of diclofenac, caused by intramuscular dosing, can be reliably evaluated by magnetic resonance imaging and should be applied early during the development of parenteral dosage forms.

Clinical Trials Registration Number: BB130/16 (Ethics Committee of the University Medicine Greifswald).

\section{Key Points}

Local tissue injury following intramuscularly administered diclofenac can be proven noninvasively by magnetic resonance imaging.

\section{Introduction}

The relief of acute pain syndromes by administration of intramuscular injections of diclofenac is still frequently practiced and seems to be a safe and well-tolerated treatment option. The incidence of local adverse events seems to be rather low- $0.05 \%$ for abscesses and $0.02 \%$ for necrosis [1]. Common reasons for local complications are bacterial contamination [2], wrong injection technique, and wrong injection site [3]. Therefore, obligatory guidelines for safe intramuscular injection, including site, dose, and injection technique, are provided by the manufacturers of parenteral diclofenac dosage forms; however, the safety issue seems to be highly underestimated. In a survey conducted between 1978 and 2003, only 171 cases with local 
injuries, including necrosis, abscess, necrotizing fasciitis and myositis, were related to the consumption of 100 million ampules of $\mathrm{Voltarol}^{\circledR}$, and only nine patients complained of pain at the injection site [4].

Since local tissue injury after diclofenac is rarely associated with relevant subjective symptoms, it can be assumed that many cases are not recognized in clinical practice. The issue may be more severe than assumed to date. In a recent experimental study in rats to investigate the disposition of intramuscularly injected depots, we incidentally observed that all animals that received an aqueous solution or oily suspension of diclofenac responded with local inflammatory intolerance [5]. This included long-lasting fluid accumulation at the site of intramuscular injection and infiltration of the muscle tissue with neutrophil granulocytes, as well as the development of necrotic changes as confirmed by magnetic resonance (MR) imaging and histopathological evaluation. The severity of inflammation was dependent on dose and the pharmaceutical formulation of the drug. To support our hypothesis that intramuscular injection of diclofenac leads to muscle damage in humans, we provide the clinical case report of a patient who gave written consent to take extra blood specimens for laboratory evaluations and determination of diclofenac pharmacokinetics, as well as for MR imaging after a medicinally indicated intramuscular diclofenac injection.

\section{Methods}

A physician (aged 65 years, body weight $90 \mathrm{~kg}$, body height $182 \mathrm{~cm}$ ) who is familiar with the safety issue described above, prescribed himself an intragluteal injection of diclofenac (Diclofenac-Ratiopharm ${ }^{\circledR} 75 \mathrm{mg} / 2 \mathrm{~mL}$; Ratiopharm, Ulm, Germany) as a result of a painful enthesopathy of the right musculus gluteus minimus, and initiated additional clinical-chemical evaluations and MR imaging of the left gluteal region to evaluate a potential muscle injury at the injection site. The diagnosis was confirmed by MR imaging approximately 1 year prior to commencement of the study. The patient commonly swallowed ibuprofen lysine $(684 \mathrm{mg})$ or diclofenac $(50 \mathrm{mg}$ ) on demand, i.e. after the occurrence of pain following stronger physical exercise. This treatment has been well tolerated. The additional diagnostic procedures have been approved by the local ethics committee under registry number BB130/16. The osmolality of the aqueous diclofenac solution was $2850 \pm 121 \mathrm{mOsmol} / \mathrm{kg}$ (Vapour Pressure Osmometer; Knauer, Berlin, Germany) and the pH was $8.19 \pm 0.03$ (Five Easy; Mettler Toledo, Greifensee, Switzerland). MR imaging in the supine position was performed using a 3-Tesla scanner (Verio; Siemens
Healthcare, Erlangen, Germany) before and 2, 12, 22, 32, 47, 62, 92, 122, 182, $242 \mathrm{~min}$ after, as well as $7.5 \mathrm{~h}$ and 1 , 2,7 and 14 days after intramuscular administration. A T2weighted turbo spin echo sequence including fat saturation was applied with the following parameters: $6960 \mathrm{~ms}$ repetition time, $91 \mathrm{~ms}$ echo time, 60 slices of $2-\mathrm{mm}$ thickness and $2-\mathrm{mm}$ spacing in between, $150^{\circ}$ flip angle, $450 \times 370 \mathrm{~mm}$ field of view, and $256 \times 170 \mathrm{~mm}$ matrix. Volume and signal intensity of the depot was assessed using the OsiriX Imaging Software 3.9 32-Bit (Pixmeo Sarl, Bernex, Switzerland). Blood was sampled via an indwelling cannula placed in a forearm vein before and 10 , 20, 30 and 45 min after, as well as 1, 1.5, 2, 2.5, 3, 3.5, 4, 5, 6,8 and 24 and $48 \mathrm{~h}$ after administration to measure plasma concentrations of diclofenac and the biomarkers creatine kinase $(\mathrm{CK})$, C-reactive protein (CRP), Procalcitonin (PCT) and Interleukin-6 (IL-6). Quantitative analysis of diclofenac concentration in plasma was performed using a validated liquid chromatography-tandem mass spectrometry (LC-MS/MS) method as previously described [5]. The biomarkers were quantified using commercially available kits for PCT (ADVIA Centaur; Siemens Healthcare, Eschborn, Germany), IL-6 (Brahms, Hennigsdorf, Germany; and Cobas e411, Roche, Mannheim, Germany), CRP and CK (Dimension Vista; Siemens Healthcare, Eschborn, Germany). All measurements were carried out according to the instructions of the manufacturer, and complied with the national regulations on laboratory quality assurance [6].

\section{Results}

The patient did not complain of pain and other symptoms at the site of diclofenac administration, neither immediately nor some time after the injection, despite the expectant attitude of the informed subject. The contralateral tendinous gluteal pain was relieved for approximately $4 \mathrm{~h}$ but occurred again thereafter, however with tolerable intensity.

Shortly after intragluteal administration of diclofenac $75 \mathrm{mg}$ in $2 \mathrm{~mL}$ aqueous solution, the recovered volume at the injection site was approximately $6 \mathrm{~mL}$, as measured using T2-weighted, MR-based volumetry. The depot volume increased to $37 \mathrm{~mL}$ within $45 \mathrm{~min}$, then decreased to $17 \mathrm{~mL}$ after approximately $4 \mathrm{~h}$, before it increased again to reach a maximum of $60 \mathrm{~mL} 24 \mathrm{~h}$ after injection. The watery inhomogeneity was seen in the MR images over several weeks. The T2-weighted signal enhancement, quantified as contrast-to-noise ratio (CNR), reached its maximum just immediately after injection, and then declined rapidly within $2 \mathrm{~h}$ to a long-lasting plateau level that disappeared after several weeks (Figs. 1,2). 


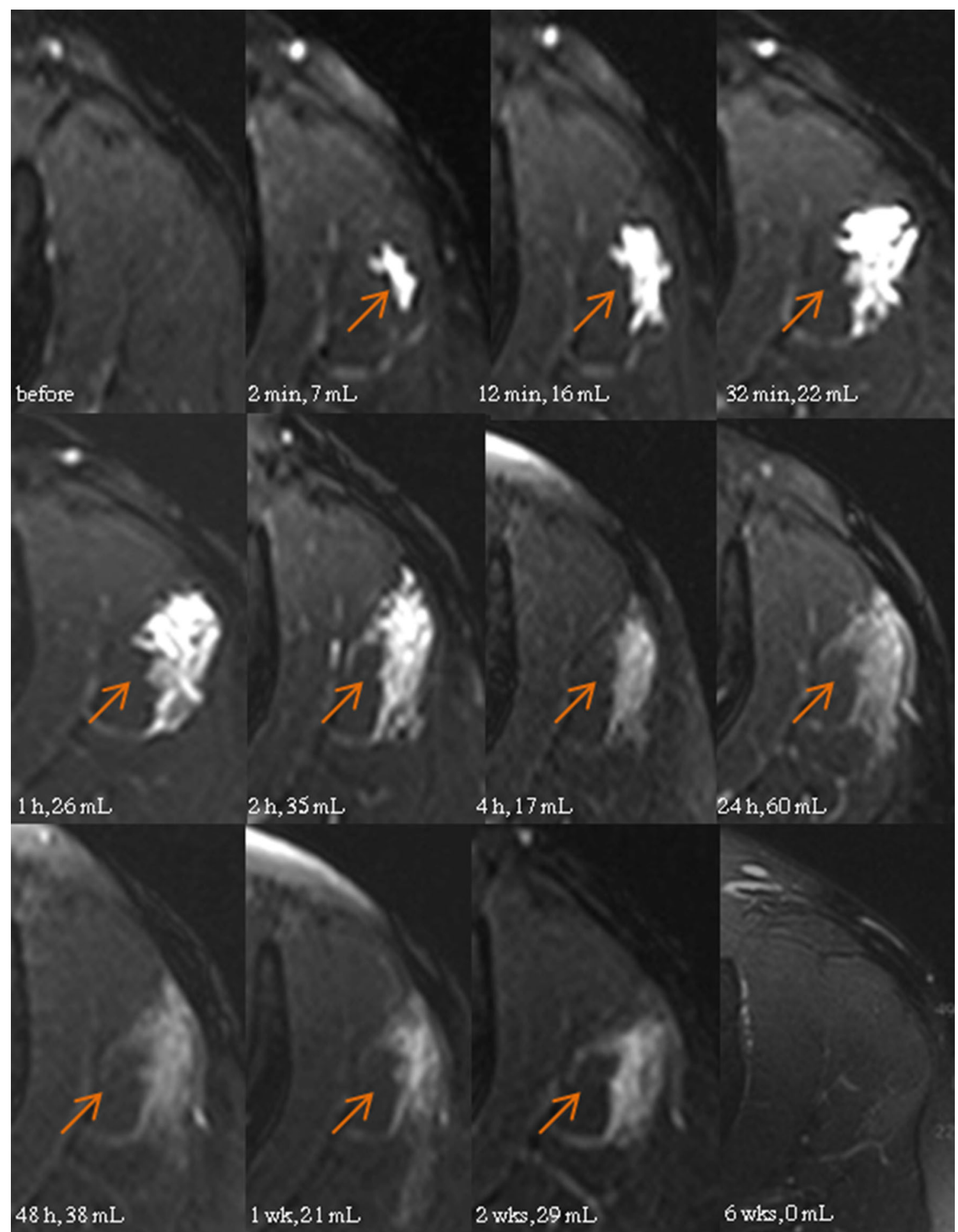

Fig. 1 T2-weighted transverse magnetic resonance images of the left gluteal region before and after a $2 \mathrm{~mL}$ injection of diclofenac watery solution. Arrows indicate the site of injection and volume of the enhanced muscle tissue

After intramuscular injection, diclofenac reached a maximum plasma concentration of approximately $1.4 \mu \mathrm{g} /$ $\mathrm{mL}$ after $30 \mathrm{~min}$ and was eliminated in a biphasic manner, with half-lives of $0.63 \mathrm{~h}$ ( $\alpha$-slope) and $1.36 \mathrm{~h}$ ( $\beta$-slope). Plasma creatine kinase activity was elevated more than sixfold within $8 \mathrm{~h}$ after diclofenac injection, and returned to baseline levels after 1 week (Fig. 2). Plasma concentrations of CRP, PCT and IL-6 were not changed from baseline after diclofenac administration. 
Fig. $2 \mathrm{CNR}$ of the T2enhanced muscle area (filled square), plasma concentrations of diclofenac $(\mathrm{ng} / \mathrm{mL}$, filled circle), and activity of creatine kinase $(\mu \mathrm{katal} / \mathrm{L}$, filled triangle $)$ after intramuscular injection of diclofenac $75 \mathrm{mg}$ in a $2-\mathrm{mL}$ solution. CNR contrast-to-noise ratio

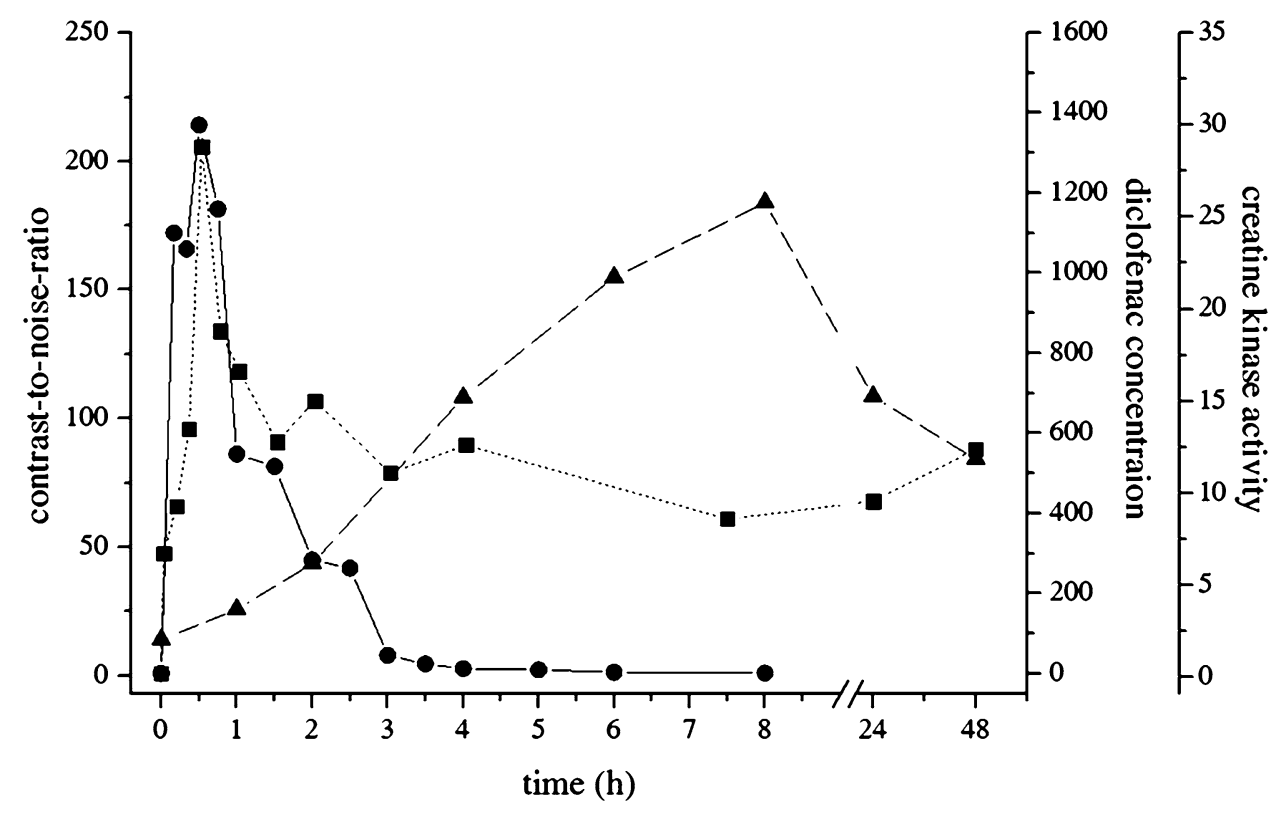

\section{Discussion}

The single MR-guided intramuscular injection of diclofenac $75 \mathrm{mg}$ in $2 \mathrm{~mL}$ solution unexpectedly damaged approximately $60 \mathrm{~mL}$ of gluteal muscle tissue of the patient, as confirmed by long-lasting, manifold enhancement of the T2-weighted MR signal in that area and elevation of the plasma CK activity for longer than $48 \mathrm{~h}$. Initially, the tissue damage was most likely triggered by local ion disequilibrium caused by infiltration of the highly hypertonic solution $(2850 \mathrm{mOsmol} / \mathrm{kg})$. This resulted in rapid enhancement of the T2-weighted MR signal, with maximum signal intensity approximately $30 \mathrm{~min}$ after injection, which was also the time of maximum diclofenac plasma exposure. This means that diclofenac must have been almost fully absorbed from the injection depot at that time. Consequently, the highest volume of the injured muscle area being detected $24 \mathrm{~h}$ after the injection cannot be explained by the osmotic pressure of the injected solution alone.

Diclofenac is known to induce organ injury indirectly by inhibition of the cyclooxygenase (e.g. gastrointestinal erosions and bleedings, renal tubular damage) or by metabolic activation of reactive metabolites that exert cell stress, impair mitochondrial functions, or trigger specific immune reactions in genetically predisposed subjects (e.g. drug-induced liver injury) [7]. However, tissue injury after intramuscular injection into the recommended gluteal region is most likely caused by direct cytotoxicity, as already observed in gastric mucosal cells [8], osteoblasts [9], and tumor cells [10]. Cell death is likely induced by activation of the caspase signaling cascade, leading to proteolytic fragmentation of DNA and degradation of the cells [11], even though the activation mechanisms of the proapoptotic signal pathways by diclofenac have not been fully understood to date. However, local toxicity of diclofenac can be influenced by the pH-dependent solubility of the drug [12]. Traces of diclofenac might precipitate at the injection site even after a minor drop in the $\mathrm{pH}$ value, as caused by local tissue congestion, ion disequilibrium, or inflammatory changes, leading to longer lasting exposure of the affected area and perpetuation of the local toxicity. The plasma CK activity, a biomarker for the muscle tissue injury, was already elevated $1 \mathrm{~h}$ after injection of the drug and reached its maximum, at the earliest, after $8 \mathrm{~h}$ (Fig. 2). The biphasic elimination profile, with half-lives of 0.63 and $1.4 \mathrm{~h}$, supports the hypothesis that parts of the dose are absorbed from a depot with a slower input rate. Furthermore, the patient did not complain of any pain at the injection site, as expected by the extent of the putative muscle injury visualized by MR imaging. The contradiction between the impressive morphological and laboratory signs and lack of clinical symptoms might also result from long-lasting tissue deposition of diclofenac, which is known to exert local anesthetic effects $[13,14]$. In that context, it should be reminded that every single rat in our previous experimental study showed a massive T2 enhancement at the injection site [5].

\section{Conclusion}

Asymptomatic tissue injury after intramuscular administration of diclofenac seems to be a frequent or regular local finding, even though the injection technique is fully in adherence with the obligatory guidelines for intramuscular 
administration in humans. Therefore, intramuscular injection of diclofenac should be carefully practiced, focusing on the individual benefit-risk balance. To our experience, local toxicity caused by intramuscular dosing of drugs can be reliably evaluated by non-invasive MR imaging, and should be applied in the very early stages of the evaluation of parenteral dosage forms.

Acknowledgements The authors thank Gitta Schumacher, Sabine Bade, Danilo Wegner, Andrea Seidel, and Stefan Hadlich for excellent technical assistance.

\section{Compliance with Ethical Standards}

Funding This work was supported by the InnoProfile grant COM_DAT [03IPT612X] of the German Federal Ministry of Education and Research (BMBF).

Conflicts of interest Mareike Probst, Jens-Peter Kühn, Christiane Modeß, Eberhard Scheuch, Anne Seidlitz, Norbert Hosten, Werner Siegmund and Werner Weitschies declare that they have no conflicts of interest.

Ethical approval All procedures performed in studies involving human participants were in accordance with the ethical standards of the institutional and/or national research committee and with the 1964 Helsinki declaration and its later amendments or comparable ethical standards.

Informed consent Informed consent was obtained from all individual participants included in the study.

Open Access This article is distributed under the terms of the Creative Commons Attribution-NonCommercial 4.0 International License (http://creativecommons.org/licenses/by-nc/4.0/), which permits any noncommercial use, distribution, and reproduction in any medium, provided you give appropriate credit to the original author(s) and the source, provide a link to the Creative Commons license, and indicate if changes were made.

\section{References}

1. Serratrice G. Study of diclofenac injectable. Tribune Med. 1982;46:43-8.
2. Rygnestad T, Kvam AM. Streptococcal myositis and tissue necrosis with intramuscular administration of diclofenac (Voltaren). Acta Anaesthesiol Scand. 1995;39:1128-30.

3. Hegan T. Non steroidals, needles and negligence. Medical Protection Society casebook. Leeds: Medical Protection Society; 2002. p. 12-3.

4. O'Sullivan DP. Intramuscular diclofenac: 25 years worldwide safety perspective is vital to consider. Response to: Wright PJ, English PJ, Hungin APS, Marsden SNE. Managing acute renal colic across the primary-secondary care interface: a pathway of care based on evidence and consensus. BMJ. 2002;325:1408-12.

5. Probst M, Kühn J-P, Scheuch E, Seidlitz A, Hadlich S, Evert K, et al. Simultaneous magnetic resonance imaging and pharmacokinetic analysis of intramuscular depots. J Control Release. 2016;227:1-12.

6. Revision of the. "Guideline of the German Medical Association on Quality Assurance in Medical Laboratory ExaminationsRili-BAEK" (unauthorized translation). J, Lab Med. 2015;39:26-69.

7. Aithal GP, Ramsay L, Daly AK, Sonchit N, Leathart JBS, Alexander G, et al. Hepatic adducts, circulating antibodies, and cytokine polymorphisms in patients with diclofenac hepatotoxicity. Hepatology. 2004;39:1430-40.

8. Kusuhara H, Matsuyuki H, Matsuura M, Imayoshi T, Okumoto T, Matsui $\mathrm{H}$. Induction of apoptotic DNA fragmentation by nonsteroidal anti-inflammatory drugs in cultured rat gastric mucosal cells. Eur J Pharmacol. 1998;360:273-80.

9. Chang J-K, Wang G-J, Tsai S-T, Ho M-L. Nonsteroidal antiinflammatory drug effects on osteoblastic cell cycle, cytotoxicity, and cell death. Connect Tissue Res. 2005;46:200-10.

10. Kim T, Jin S, Kim W, Kang E, Choi K, Kim H, et al. Prolonged activation of mitogen-activated protein kinases during NSAIDinduced apoptosis in HT-29 colon cancer cells. Int J Colorectal Dis. 2001;16:167-73.

11. Gómez-Lechón MJ, Ponsoda X, O’Connor E, Donato T, Jover R, Castell JV. Diclofenac induces apoptosis in hepatocytes. Toxicol In Vitro. 2003;17:675-80.

12. Ledwidge MT, Corrigan OI. Effects of surface active characteristics and solid state forms on the $\mathrm{pH}$ solubility profiles of drugsalt systems. Int J Pharm. 1998;174:187-200.

13. Cairns BE, Mann MK, Mok E, Dong X-D, Svensson P. Diclofenac exerts local anesthetic-like actions on rat masseter muscle afferent fibers. Brain Res. 2008;1194:56-64.

14. Nakamura M, Jang I-S. pH-dependent inhibition of tetrodotoxinresistant $\mathrm{Na}+$ channels by diclofenac in rat nociceptive neurons. Prog Neuropsychopharmacol Biol Psychiatry. 2016;64:35-43. 